Strauss, B. S. \& Minagawa, T. (1959). J. gen. Microbiol. 20, 237-245

\title{
The Formation of Methionine by a Methionine- Requiring Mutant of Neurospora crassa
}

\author{
By B. S. STRAUSS* aNd T. MINAGAWA $\dagger$ \\ Department of Zoology, Syracuse University, \\ Syracuse 10, Nere York, U.S.A.
}

\begin{abstract}
SUMMARY : A methionine-requiring mutant of Neurospora crassa incorporated ${ }^{35} \mathrm{SO}_{4}$ into methionine. This incorporation represents net synthesis of methionine by the mutant. It is quite likely that methionine synthesis proceeds by the normal pathway in the mutant. Not all of the normal proteins can be synthesized when methionine supplies are limiting, accounting for the inability of the mutant to begin growth without a long lag even though methionine can be synthesized.
\end{abstract}

In the course of our investigations on the lethal effect of incorporated ${ }^{35} \mathrm{~S}$ in Neurospora (Strauss, 1958b) we decided to study the effect of sulphur distribution on the radiation sensitivity of conidia. It seemed likely that we could compare the relative 'importance' of the incorporation of ${ }^{35} \mathrm{~S}$ into cysteine or into methionine by comparing the lethality of ${ }^{35} \mathrm{SO}_{4}$ incorporated into a wild type and into a methionine-requiring mutant. We supposed that the wild type would incorporate sulphur into protein cysteine and methionine but that the mutant would incorporate sulphur only into cysteine. The growth characteristics of the mutant indicated that it should not be able to synthesize methionine. When the experiment was done we found that there was very little difference in the distribution of labelled sulphur in the conidia of the mutant compared to the wild type grown with ${ }^{35 \mathrm{SO}_{4}}$ and non-labelled methionine. Protein hydrolysates from both these strains appeared to have ${ }^{35} \mathrm{~S}$ incorporated into methionine. Since this behaviour was unexpected we decided to investigate this methionine-requiring strain in more detail. Although 'leaky' mutants have been described before (Bonner, 1951; Bonner, Yanofsky \& Partridge, 1952) we hoped to be able to account for the ability of a mutant to synthesize the substance it requires for growth although unable to grow in the absence of added substance.

\section{METHODS}

The methionine-requiring mutant used in these studies was received from Dr A. Srb bearing the isolation number 584. Dr Srb informed us that mutant 584 was obtained by the method of Woodward, De Zeeuw \& Srb (1954) following ultraviolet irradiation of wild-type conidia of Neurospora crassa. Crosses of the mutant to wild-type indicated no significant deviation

* Temporary address : Department of Genetics, Osaka University Medical School, Kitaku, Osaka, Japan.

$\dagger$ Temporary address: Carnegie Institution of Washington, Cold Spring Harbor, Long Island, New York. Permanent address : Department of Biology, Kobe University. 
from the expected ratio in the progeny from a single factor cross. Of the limited number of selected ascospores which germinated and were tested there were ninety-one wild-type and eighty-seven mutant cultures obtained. There were no obvious differences between the mutant progeny when incubated in minimal medium or with methionine. Strain 584 shows no growth after 3 days in minimal medium at $30^{\circ}$ (Beadle \& Tatum, 1945). Good growth was obtained on the addition of L- or DL-methionine to minimal medium or on the addition of either methionine sulphoxide or homocysteine. No growth was obtained

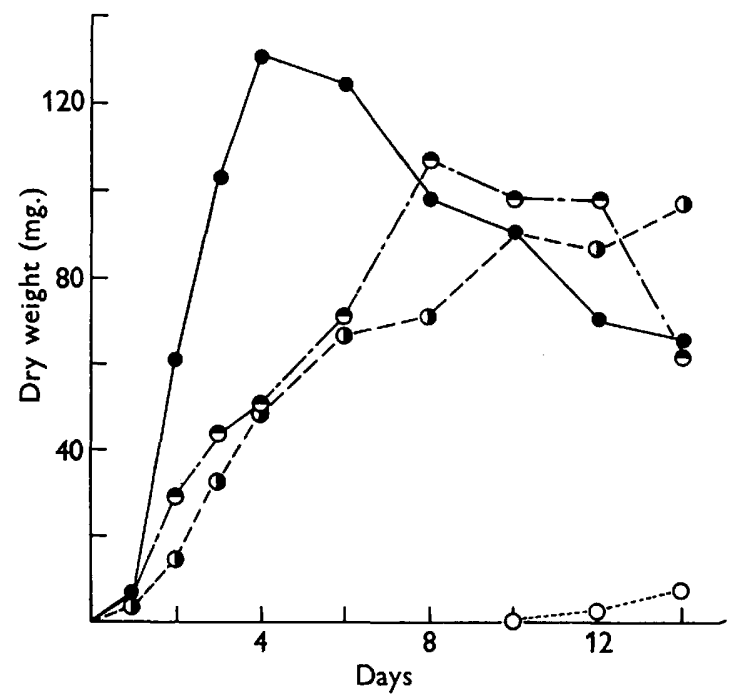

Fig. 1. Growth of the methionine-requiring Neurospora mutant with different amounts of L-methionine. Growth was determined as mg. dry weight of mycelium produced after incubation for the indicated period of time in standing culture at $30^{\circ}$ in $125 \mathrm{ml}$. Erlenmeyer flasks containing $20 \mathrm{ml}$. minimal medium + the following additions: $\mathrm{O}-\mathrm{O}=$ no addition; $-\mathrm{O}=+10 \mathrm{mg}$. L-methionine; $\theta-\theta=+1.0 \mathrm{mg}$. L-methionine; $\mathrm{O}-\mathrm{O}=+0.5 \mathrm{mg}$. L-methionine.

when either cystathionine, homoserine, cysteine, cystine, taurine, cysteic acid, thiosulphate or sulphite was added to minimal medium. The mutant acted as though it had a genetic block in the conversion of cystathionine to homocysteine. A typical growth-response curve was obtained when the dry weight of mycelium produced after 3 days growth at $30^{\circ}$ is determined as a function of methionine concentration. The final dry weight attained was independent of the amount of methionine added; once growth had begun it continued until a maximum weight was reached (Fig. 1).

Measurement and location of ${ }^{35 \mathrm{~S}}$ and S-containing compounds. In the experiments which follow the methionine-requiring mutant and the wild-type were grown, or incubated, in a medium modified to permit control of the amount of sulphur added. $\mathrm{MgCl}_{2}$ was substituted for the corresponding sulphate in minimal medium and a trace element supplement was used which contained no sulphur (Strauss, Vaharu \& Frickey, 1956). Carrier-free ${ }^{{ }^{35} \mathrm{SO}_{4} \text { was }}$ 
obtained from Oak Ridge and diluted to an appropriate specific activity. Conidia were obtained as described previously (Strauss, 1958a). Our methods for handling Neurospora were those in standard use. Mycelia or conidia were fractionated for the identification and determination of sulphur compounds by a slight modification of the methods described by Roberts et al. (1955). The protein amino acids were obtained by extracting the mould with aqueous ethanol, then with warm ethanol + ether $(3: 1)$ and with warm $\left(70^{\circ}\right)$ trichloroacetic acid. The residue was washed, dried and then hydrolysed with $6 \mathrm{~N}-\mathrm{HCl}$ by autoclaving at $15 \mathrm{lb}$./sq.in. for $2 \mathrm{hr}$. in a glass-stoppered tube. The hydrolysate was evaporated to dryness several times in vacuo over phosphorus pentoxide and sodium hydroxide in order to remove excess $\mathrm{HCl}$. The resulting amino acid mixture was then made to volume and chromatographed in a descending system in a phenol + water mixture. Radio-active areas on the chromatograms were detected by scanning with a 'Forro' chromatogram scanner (Forro Radiochemical Co., Chicago) connected to an Esterline-Angus recorder (Esterline Angus Co., Indianapolis) through a Nuclear ratemeter (Nuclear, Chicago). The radio-active areas were occasionally eluted for further analysis. Radio-active free amino acids were extracted by treating the mould with $70 \%(\mathrm{v} / \mathrm{v})$ ethanol in water.

Recognition of the two sulphur amino acids found in protein is relatively simple, since the amino acids of the cysteine family have low $\boldsymbol{R}_{f}$ values when chromatographed in a phenol + water system, while the methionine family has the relatively high $\boldsymbol{R}_{f}$ value characteristic of the more aliphatic compounds (Block, Durrum \& Zweig, 1955). The sulphur amino acids may exist in a variety of oxidized forms; methionine, for example, may be identified as the sulphoxide or the sulphone. The exact proportion of each form obtained seems to depend on the conditions of hydrolysis. Many workers prefer to complete the oxidation before chromatography but we chromatographed our material directly and attempted to identify the particular oxidation products by chromatography in a second solvent system which separates the oxidation forms. Since we were unable to find a solvent system which satisfactorily separated the cysteine family from cystathionine a paper electrophoresis method was used. Electrophoresis at $14 \mathrm{v} . / \mathrm{cm}$. on Whatman $3 \mathrm{MM}$ paper (hanging freely from supports) for 4-5 hr., using 0.25 M-acetic acid (pH 2.8) separated cysteine and cystathionine. The cystathionine moved an average of $3.6 \mathrm{~cm}$. $/ \mathrm{hr}$., the cysteine $3.0 \mathrm{~cm}$. $/ \mathrm{hr}$., under these conditions.

\section{RESULTS}

Mutant conidia, obtained from cultures grown with $2.5 \mu$ mole ${ }^{35} \mathrm{SO}_{4}$ plus $4 \mu$ moles of non-labelled methionine in a modified liquid Westergaard medium (Strauss et al. 1956), contained labelled methionine. The scanning pattern of the mutant protein hydrolysate was only slightly different from the wild-type pattern. In several experiments we inoculated the conidia, produced during growth of strain 584 with ${ }^{35} \mathrm{SO}_{4}$, into minimal medium. No growth resulted until methionine was added, indicating that the conidia were still mutant. 
Wild-type (74, A) incorporated more ${ }^{35} \mathrm{SO}_{4}$ into the methionine of its protein than into the cysteine. This pattern applied also to uniformly-labelled conidia as well as to non-labelled conidia incubated for $2 \mathrm{hr}$. in sulphur-limiting medium. There was a difference in the distribution of incorporated sulphur in conidia uniformly labelled and in those incubated for a short time in medium with labelled sulphate but this difference was mainly due to differences in the relative amounts of incorporation into the soluble and residual fractions (Table 1).

\section{Table 1. Distribution of ${ }^{35} S$ in Neurospora conidia}

Wild-type conidia $\left(3.5 \times 10^{8}\right)$ were incubated for $2 \mathrm{hr}$. at $30^{\circ}$ with aeration. Uniformly labelled conidia were obtained from cultures of wild-type 74. A grown for 5 days in a liquid Westergaards medium containing $5 \mu$ mole sulphur (as ${ }^{35} \mathrm{SO}_{4}$ )/flask.

\begin{tabular}{|c|c|c|}
\hline \multirow[b]{2}{*}{ Fraction } & \multicolumn{2}{|c|}{$\%$ total sulphur in each fraction } \\
\hline & $\begin{array}{c}\text { Incubated } 2 \mathrm{hr} \text {. } \\
\text { with } 0 \cdot 3 \mu \text { mole } \mathrm{SO}_{4}\end{array}$ & $\begin{array}{l}\text { Uniformly } \\
\text { labelled }\end{array}$ \\
\hline \multicolumn{3}{|l|}{ Soluble in: } \\
\hline Cold trichloroacetic acid & $27 \cdot 5$ & $10 \cdot 0$ \\
\hline Ethanol & $1 \cdot 5$ & $4 \cdot 3$ \\
\hline Ethanol + ether & $3 \cdot 9$ & $1 \cdot 0$ \\
\hline $\begin{array}{l}\text { Warm trichloroacetic acid } \\
(\mathrm{TCA})\left(4 \times \text { at } 70^{\circ}\right)\end{array}$ & $\mathbf{2 \cdot 4}$ & $3 \cdot 8$ \\
\hline Residue & $64 \cdot 6$ & $80 \cdot 8$ \\
\hline $\left.\begin{array}{l}\% \text { in last water wash } \\
\text { before TCA }\end{array}\right\}$ & $0 \cdot 2$ & - \\
\hline
\end{tabular}

The identity of the material with the higher $\boldsymbol{R}_{f}$ value in these chromatograms was confirmed as being methionine, by the correspondence of the peaks of radio-activity (after phenol + water chromatography) with the spots of ninhydrin-reacting substance obtained by adding methionine or methionine sulphoxide (non-labelled) to the hydrolysates. The 'methionine spots' from phenol + water chromatograms of both wild-type and mutant preparations were eluted, evaporated and re-chromatographed in a butanol + acetic acid solvent, along with methionine and methionine sulphoxide standards. The 'methionine spot' from both mutant and wild-type preparations was a mixture of methionine and methionine sulphoxide showing that the mutant really did form labelled methionine.

Even though there was no visible germination (outgrowth production) by the wild-type after $2 \mathrm{hr}$. of incubation in low sulphur medium there was a definite synthesis of RNA (Table 2). Nucleic acid was determined in Neurospora by a method recently devised in our laboratory (Minagawa, Wagner \& Strauss, 1959). Considering the well-established relationship between nucleic acid and protein synthesis (Cohn \& Volkin, 1957), we believe that these data indicate that net protein synthesis occurred during a 2-hr incubation in low sulphur medium. It is obvious that net protein synthesis must have occurred in the course of producing a mycelial pad from an inoculum of conidia.

We were careful to check for traces of contamination by other organisms or by wild-type Neurospora in these experiments, since even a trace of 
methionine synthesis by contaminating organisms might account for our results. When incorporation into the mycelium was studied, parallel inoculations were made on minimal medium and a small piece of the mycelium produced was inoculated into minimal medium to make sure that the produced mycelium was still methionine-requiring. When conidial suspensions were incubated for short periods of time in the absence of methionine, portions of the suspension were inoculated into minimal medium at the start of the experiment and in addition a portion of the incubated material was examined with the oil-immersion lens for traces of bacterial growth.

\section{Table 2. Nucleic acid synthesis during short term incubation of wild-type $74 \mathrm{~A}$}

Wild-type conidia $\left(3.5 \times 10^{8}\right)$ were incubated in $35 \mathrm{ml}$. modified minimal medium with aeration at $30^{\circ}$.

DNA = difference in optical density at $265-290 \mathrm{~m} \mu$; extract diluted to $10 \mathrm{ml}$.

RNA = difference in optical density $260-290 \mathrm{~m} \mu$; extract diluted to $100 \mathrm{ml}$. and optical density multiplied by 10 .

$\begin{array}{cccccc}\begin{array}{c}\text { Period of } \\ \text { incubation (hr.) }\end{array} & \begin{array}{c}\mathrm{SO}_{\mathbf{4}} \text { added } \\ (\mu \mathrm{mole})\end{array} & \begin{array}{c}\text { DNA } \\ (265-290 \mathrm{~m} \mu)\end{array} & \begin{array}{c}\text { Increase } \\ (\%)\end{array} & \begin{array}{c}\text { RNA } \\ (260-290 \mathrm{~m} \mu)\end{array} & \begin{array}{c}\text { Increase } \\ (\%)\end{array} \\ 0 & - & 0 \cdot 147 & - & 2 \cdot 04 & - \\ 2 & & 0 \cdot 130 & & 1 \cdot 76 & \\ 2 & 0 \cdot 0 & 0 \cdot 163 & 17 & 2 \cdot 74 & 34 \\ & & 0 \cdot 162 & & 2 \cdot 35 & \\ 2 & 0 \cdot 15 & 0 \cdot 159 & 17 & 3 \cdot 17 & 61 \\ & & 0 \cdot 166 & & 2 \cdot 93 & \\ & 1 \cdot 2 & 0 \cdot 163 & 17 & 3 \cdot 86 & 103\end{array}$

After $15.5 \mathrm{hr}$. of incubation in a minimal medium the incorporation of ${ }^{35} \mathrm{SO}_{4}$ into the protein fraction of the methionine-requiring mutant was readily detected (Fig. 2). This radio-active material was identified as methionine by the method described above. Although labelled methionine was found in the protein fraction it was evident from an examination of the chromatogram tracings that the mutant contained less radio-active methionine relative to cysteine in its protein than the wild-type. In a separate experiment in which the two areas of the chromatograms of the protein hydrolysates were eluted, dried and counted, the methionine:cysteine ratio from the wild-type was $2 \cdot 4$ while the mutant ratio was $0 \cdot 69$. Incubation of the mutant in medium containing methionine gave a methionine: cysteine ratio of $1 \cdot 19$. Incubation of the mutant for shorter periods of time in minimal medium gave an even smaller methionine:cysteine ratio. Incubation of strain 584 for $9 \mathrm{hr}$. in minimal medium (with ${ }^{35} \mathrm{SO}_{4}$ of lower specific activity) gave a protein hydrolysate in which the cysteine was definitely labelled but in which the radioactive methionine area was not visible above the background. It should be emphasized that the free amino acid pool of wild-type conidia or of wild-type organism incubated under these conditions did not contain detectable methionine (see below). The relatively large difference between wild-type and mutant in the radio-active methionine:cysteine ratio was not seen in conidial 
preparations or in preparations from mutant and wild-type mycelium grown with methionine.

The free amino acid pool (extractable with warm $70 \%(w / v)$ ethanol in water or with cold trichloroacetic acid) of the wild-type contained cystathionine and glutathionine (Table 3) but did not contain detectable methionine. The methionine-requiring mutant also contained cystathionine and glutathione but the relative amounts were different from the wild-type. The mutant, grown with methionine, did not contain detectable radio-active glutathione
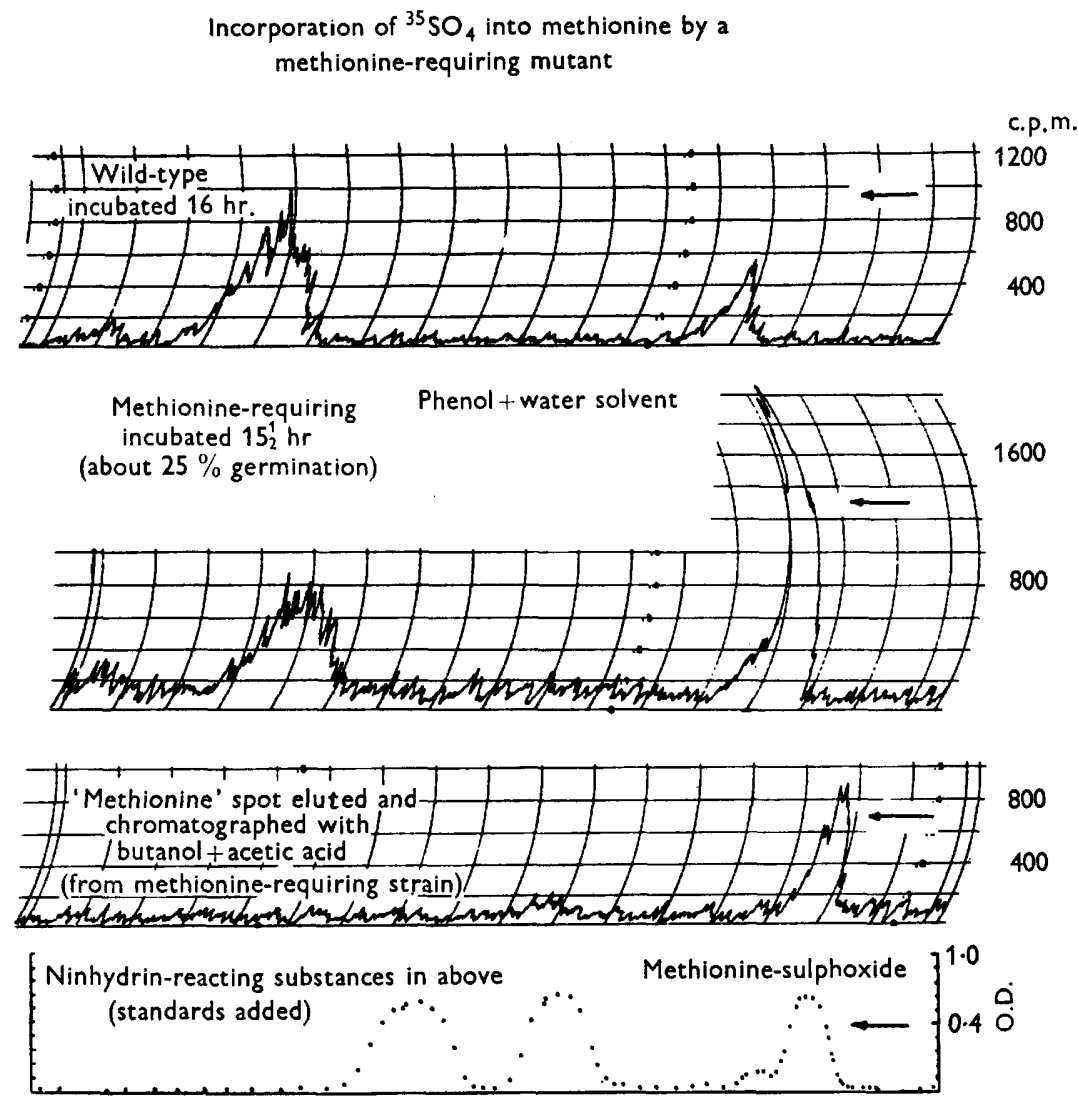

Fig. 2. Scanning patterns of the protein hydrolysate of conidia incubated overnight in minimal medium containing ${ }^{35} \mathrm{SO}_{4}$. About $2 \times 10^{8}$ non-labelled conidia were shaken overnight at $28^{\circ}$ in $50 \mathrm{ml}$. modified minimal medium contained in $250 \mathrm{ml}$. Erlenmeyer flasks. The wild-type organism was incubated in media containing $3 \mu$ mole sulphate $(10 \mu \mathrm{c}$.). The methionine-requiring mutant was incubated with $2 \mu$ mole sulphate $(20 \mu \mathrm{c}) /$ $50 \mathrm{ml}$. After incubation the material was treated as described in the text. Arrows indicate the direction of flow of the chromatograms. The start and finish of the chromatograms are indicated by vertical lines. The methionine area was eluted from separate chromatograms, evaporated and rechromatographed in a butanol + acetic acid solvent mixture. Methionine and methionine sulphoxide(non-labelled) were added as standards. The ninhydrin-reacting material was recorded by plotting the optical density of the treated chromatogram as read with a 'Photovolt' densitometer. The position of the methionine sulphoxide spot as determined with separate standards is indicated on the figure. 
after 2 days of growth, but did contain cystathionine. After 4 days the amount of cystathionine had decreased and glutathionine was visible. No sulphurcontaining amino acids were detectable in the ethanolic extract of the mycelium after 6 days of incubation. No cystathionine was detected in the medium in which the methionine-requiring mutant was grown.

\section{Table 3. Fractionation of the fraction of mycelium soluble in $70 \%(v / v)$ ethanol in water}

The numbers record the position of ninhydrin positive areas. Radio-active spots are italicized. Parentheses indicate ninhydrin-negative radio-active spots. The mycelium of the methionine-requiring mutants was harvested after 2,4 or 6 days incubation in standing culture at $30^{\circ}$ in $20 \mathrm{ml}$. minimal medium containing ${ }^{85} \mathrm{SO}_{4}$ and $0.5 \mu$ mole $\mathrm{L}$-methionine. The mycelium was washed with water and dried in vacuo. Twelve mg. dried mycelium were extracted with boiling $70 \%(\mathrm{v} / \mathrm{v})$ ethanol in water for $30 \mathrm{~min}$.; the extract was made up to $5 \mathrm{ml}$. and portions were chromatographed in phenol + water solvent. The wild type was grown in the absence of added methionine. Two-day wild-type cultures compared in dry weight to the 4-day mutant cultures described above. The area corresponding to cystathionine could not be distinguished from cysteine by paper chromatography. The extract was subjected to electrophoresis as described in the text. The identity of the various spots was checked by electrophoresis of superimposed standards. We assume that the radio-activity at the origin of the chromatograms was due to inorganic sulphate; the material at the finish of the chromatograms of the mutant after 4 days and the wild type after 2 days is unknown. A. Ninhydrin-positive and radio-active spots after phenol + water
chromatography

Period of incubation

$\begin{array}{cc}\text { Strain } & \text { (days) } \\ \mathbf{7 4} \mathbf{A} & \mathbf{2} \\ \mathbf{5 8 4} & \mathbf{2} \\ \mathbf{5 8 4} & \mathbf{4} \\ \mathbf{5 8 4} & \mathbf{6}\end{array}$

$\begin{array}{rllllllll}\text { (4) } & 15 & 26 & & \mathbf{3 9} & \mathbf{4 6} & \mathbf{5 7} & \mathbf{7 1 - 9 1} & (96) \\ (2) & - & 27 & & \mathbf{3 5} & \mathbf{4 7} & \mathbf{5 6 ,}, \mathbf{5 9} & & \\ (2) & 16 & 26 & & \mathbf{3 9} & \mathbf{4 5} & \mathbf{5 6} & \mathbf{7 2 - 8 9} & (99) \\ - & - & - & \mathbf{2 9} & \mathbf{3 4} & \mathbf{4 5} & \mathbf{5 2 ,} \mathbf{5 7} & & \end{array}$

$R_{,}$values of standards: methionine $=83$, methionine sulphoxide $=78$, cystathionine $=29$, cysteine $=27$, oxidized glutathione $=16$.

B. Ninhydrin positive and radio-active spots after electrophoresis

\begin{tabular}{|c|c|c|c|c|c|}
\hline \multirow{2}{*}{$\begin{array}{r}\text { Strain } \\
74 \mathrm{~A}\end{array}$} & $\begin{array}{c}\text { Period of } \\
\text { incubation } \\
\text { (days) }\end{array}$ & \multicolumn{4}{|c|}{$\begin{array}{c}\text { Relative mobility } \\
\text { (in \% of the cystein } \\
\text { mobility) }\end{array}$} \\
\hline & 2 & - & 72 & 90 & 122 \\
\hline $74 \mathrm{~A}$ & 2 & - & 62 & - & 118 \\
\hline \multicolumn{6}{|c|}{ ( + added glutathionine) } \\
\hline 584 & 2 & - & — & 96 & 120 \\
\hline 584 & 4 & 0 & 71 & 90 & 126 \\
\hline 584 & 4 & 0 & 69 & & 118 \\
\hline
\end{tabular}

Relative mobility of standards: cystathionine $=122$, methionine $=111$, methionine sulphoxide $=100$, cysteine $=100$, reduced glutathione $=67$.

\section{DISCUSSION}

We believe that the incorporation of ${ }^{35} \mathrm{~S}$ from sulphate into methionine by the methionine-requiring mutant represents net synthesis of methionine. The growth data indicate that the mutant was eventually able to synthesize its protein (and therefore to synthesize methionine), since traces of growth were 
obtained in minimal medium after an extended growth lag and since a maximum yield of mycelium was obtained once growth had started. Incorporation of sulphur into methionine occurred during a period of protein synthesis as judged by the increase in nucleic acid (in the wild-type), by germination and by the production of a visible mycelium by the mutant in the presence of added non-labelled methionine. There are no exchange reactions known, at present, which might account for the reduction of sulphate and its binding to an organic molecule. We suspect that methionine is not synthesized by an alternative pathway although our data are not conclusive. If methionine is synthesized via cystathionine (Horowitz, 1950), cystathionine should accumulate at the start of growth, because of the genetic block. Since the block is 'leaky' the cystathionine should gradually disappear as the limited sulphur supply in the medium is used up and as methionine is formed, as we found. The synthesis of methionine by the mutant began rapidly and it seems probable that the use of ${ }^{35} \mathrm{SO}_{4}$ of high enough specific activity would permit detection of methionine synthesis after any period of incubation.

We think that the data contain an answer to the question: 'why, if the mutant can synthesize methionine, is there such a long lag before growth begins on minimal medium?'. The total mixture of wild-type protein (grown with ${ }^{35} \mathrm{SO}_{4}$ as the sole sulphur source) contains more methionine than cysteine. The ratio of ${ }^{35} \mathrm{~S}$-methionine: ${ }^{35} \mathrm{~S}$-cysteine in either the mycelium or the conidia of the mutant (grown in the presence of non-labelled methionine) is not very different from that of the wild-type grown under the same conditions. The ratio of protein methionine: cysteine formed from ${ }^{35} \mathrm{SO}_{4}$ by wild-type appears to be the same regardless of the duration of incubation or of the amount of sulphur in the medium. Although the wild-type ratio is relatively constant (judged from the chromatogram tracings) the behaviour of the mutant was quite different. The ratio of protein methionine:cysteine from ${ }^{35} \mathrm{SO}_{4}$ after $16 \mathrm{hr}$. was much lower than is characteristic of wild-type protein. Utilization of non-labelled stored methionine by the methionine-requiring mutant might account for these low ratios, since protein would be formed with this nonlabelled methionine, but with cysteine produced from ${ }^{35} \mathrm{SO}_{4}$. However, there was no free methionine detectable in the amino-acid fraction of conidia or of mycelium. Glutathione, a peptide containing cysteine, was present. We suppose therefore that methionine was produced slowly by the normal pathway from the start of incubation and that the rate of methionine synthesis increased as growth proceeded.

The lower methionine:cysteine ratio in the newly formed mutant protein indicates that only a portion of the normal Neurospora proteins were made after incubation of the mutant for brief periods in minimal medium. Certain proteins, relatively rich in cysteine compared to methionine, must be able to compete more successfully for the limited supplies of newly-synthesized methionine made available by the mutant. We suppose that the mutant was not able to grow until those proteins, relatively richer in methionine than in cysteine, had been made. Growth is not possible from the start even though the required factor could be made. 
In his study of the 'leaky' tryptophan-requiring mutants Bonner (1951) showed that seven out of the nine mutants tested made the substance they required. We suspect that this ability, demonstrated once again with the single methionine-requiring mutant reported herein, is fairly widespread. Many mutants, incubated on minimal medium, die off because of 'starvation death' (Strauss, 1958a). It is therefore not possible to determine whether they can make the factor they require, since the conidia (or mycelia) die as soon as starvation conditions arise because of exhaustion of growth factor. The phenomenon of 'leakage' described by Bonner may actually be typical for the class of nutritionally-deficient mutants.

This work was supported in part by contract AT (30-1) 1138 between Syracuse University and the U.S. Atomic Energy Commission and by a grant from the National Science Foundation.

\section{REFERENCES}

Beadle, G. W. \& TATuM, E. L. (1945). Neurospora. II. Methods of producing and detecting mutations concerned with nutritional requirements. Amer. J. Bot. 32, 678.

Block, R. J., Durrum, E. L. \& Zweig, G. (1955). A Manual of Paper Chromatography and Paper Electrophoresis, 484 pp. New York: Academic Press, Inc.

BonNer, D. M. (1951). Gene-enzyme relationships in Neurospora. Cold. Spr. Harb. Symp. quant. Biol. 16, 143.

Bonner, D. M., Yanofsky, C. \& Partridge, C. W. H. (1952). Incomplete genetic blocks in biochemical mutants of Neurospora. Proc. nat. Acad. Sci., Wash. $38,25$.

Cohn, W. E. \& Volkin, E. (1957). The nucleic acids. Ann. Rev. Biochem. 26, 491.

Horowitz, N. H. (1950). Biochemical genetics of Neurospora. Advanc. Gentet. $3,33$.

Minagawa, T., Wagner, B. \& Strauss, B. (1959). The nucleic acid content of Neurospora crassa. Arch. Biochem. Biophys. (in the Press).

Roberts, R. B., Abelson, P. H., Cowie, D. B., Bolton, E. T. \& Britten, R. J. (1955). Studies of biosynthesis in Escherichia coli. Publ. Carneg. Instn, No. 607.

Strauss, B. S., Vaharu, T. \& Frickey, P. (1956). Studies on the lethal effect of incorporated $\mathrm{P}^{32}$ and $\mathrm{S}^{35}$ in Neurospora crassa. Rad. Res. 5, 25.

Strauss, B. S. (1958a). Cell death and 'unbalanced growth' in Neurospora. J. gen. Microbiol. 18, 658.

Strauss, B. S. $(1958 b)$. Effect of the distribution of incorporated sulfur on the lethal effect of incorporated ${ }^{35} \mathrm{SO}_{4}$. Proc. 10th Int. Congr. Genet. (in the Press).

Woodward, V. W., DeZeEuw, J. R. \& SrB, A. M. (1954). The separation and isolation of particular biochemical mutants of Neurospora by differential germination of conidia followed by filtration and selective plating. Proc. nat. Acad. Sci., Wash. 40, 192. 